\title{
Split-brain syndrome and extended perceptual consciousness
}

\author{
Adrian Downey ${ }^{1}$
}

Published online: 25 November 2017

(C) The Author(s) 2017. This article is an open access publication

\begin{abstract}
In this paper I argue that split-brain syndrome is best understood within an extended mind framework and, therefore, that its very existence provides support for an externalist account of conscious perception. I begin by outlining the experimental aberration model of split-brain syndrome and explain both: why this model provides the best account of split-brain syndrome; and, why it is commonly rejected. Then, I summarise Susan Hurley's argument that splitbrain subjects could unify their conscious perceptual field by using external factors to stand-in for the missing corpus callosum. I next provide an argument that split-brain subjects do unify their perceptual fields via external factors. Finally, I explain why my account provides one with an experimental aberration model which avoids the problems typically levelled at such views, and highlight some empirical predictions made by the account. The nature of split-brain syndrome has long been considered mysterious by proponents of internalist accounts of consciousness. However, in this paper I argue that externalist theories can provide a straightforward explanation of the condition. I therefore conclude that the ability of externalist accounts to explain split-brain syndrome gives us strong reason to prefer them over internalist rivals.
\end{abstract}

Keywords Enactive cognitive science - Ecological psychology Externalism about consciousness $\cdot$ Split-brain syndrome $\cdot$ Skill acquisition

\section{Introduction}

In this paper I provide an externalist account of split-brain syndrome. I argue that splitbrain subjects compensate for the now missing corpus callosum by using factors

Adrian Downey

downeya@adf.bham.ac.uk

1 Department of Philosophy, School of Philosophy, Theology, and Religion University of

Birmingham, Edgbaston, Birmingham B15 2TT, UK 
external to the brain (whether bodily or environmental or both) to pass information across hemispheres, and claim that these external factors ${ }^{1}$ play a constitutive role in unifying the subjects' conscious perceptual field. I contend that this unification of consciousness occurs via the learning of a new sensorimotor skill — which I label "constitutive-cross-cueing" - and provide an empirical argument for this position which generates testable hypotheses. I conclude that externalist accounts of splitbrain syndrome provide a strong explanation of the condition and that this gives us good reason to accept such accounts.

The paper itself is structured as follows - in section two I explain what split-brain syndrome is, summarise the experimental aberration model of the condition, and outline the objections commonly levelled at it. In section three I summarise Susan Hurley's argument that split-brain subjects could unify their consciousness via external factors and then, in sections four and five, I provide an empirical argument for the claim that subjects actually do unify their conscious fields via external means. Finally, in section six, I explain why externalist accounts are particularly well-equipped to provide an endorsement of this account and highlight a number of predictions which follow directly from it.

\section{Split-brain syndrome and the experimental aberration model}

During the mid-twentieth century patients suffering from severe epilepsy underwent the surgical procedure which I will label the "split-brain procedure". During this procedure the corpus callosum, which is a band of nerve fibres that connects the brain's left and right hemispheres, is severed. Severing the corpus callosum helps in the treatment of epilepsy because seizure patterns can no longer spread throughout the brain. Aside from treating epilepsy, the split-brain procedure has the unintended side-effect of removing the main channel through which the brain's hemispheres communicate. When the corpus callosum is severed the left and right hemispheres become anatomically isolated from one another. ${ }^{2}$ In everyday life split-brain subjects are (generally) indistinguishable from their healthy human counter-parts. They claim to feel no different after undergoing surgery, and their friends and families do not notice any differences between the subjects pre- and post- surgery. Similarly, animals which have been subjected to split-brain surgery do not appear to behave any differently after it, and their con-specifics do not appear to notice any differences. Thus, split-brain surgery appears to have a negligible effect on the everyday life and behaviour of organisms which have undergone the procedure.

A prototypical experiment on a split-brain subject would go as follows: the subject will be seated in front of a screen and instructed to fixate on a central marker. By having

\footnotetext{
${ }^{1}$ Henceforth, when I use the term "external factors", this should be taken as short-hand for "factors external to the brain (whether bodily or environmental)." The term "factors", meanwhile, should be considered to act as a synonym for the term "vehicle". For example, the laptop in front of me will count as an external factor which is constitutive of my present visual experience. Thus, an external factor will not be simply anything external to the brain. Rather, it will be something which is external and yet plays a constitutive role in perception. The reason I use the term "factor", as opposed to "vehicle", is because I want my argument to be compatible with both representational and non-representational accounts of mind. (My thanks to an anonymous reviewer for pushing me to say more about this definition and clarify it).

${ }^{2}$ Sub-cortical connections are unaffected by the procedure (Gazzaniga 2000).
} 
the subject fixate on a central marker the experimenter can ensure that subsequently presented stimuli will be localised to a single hemisphere. The subject is then asked to engage in a goal-directed behaviour which is linked to the stimulus. Provided the experiment has been carried out correctly and the experimental stimuli were localised to a single hemisphere, the subject will engage in autonomous goal-directed behaviours, with one of these behaviours being controlled by the left hemisphere and the other controlled by the right. Split-brain subjects behave in this strange manner because each of their hemispheres is informationally isolated from the other. Neither hemisphere has access to the stimulus processed by the other, and so when the subject is asked to engage in goal-directed behaviour in response to the stimulus perceived each hemisphere supports intentional action related to the stimulus it has been exposed to.

Scientists were surprised at the results of split-brain experiments because, aside from the experiments themselves, split-brain subjects behave surprisingly normally. Consider the following comment by Springer and Deutsch:

The frequency with which these stories are mentioned makes it easy to forget that they describe rare incidents that are viewed as strange, isolated incidents even by the people involved. Thus, a pattern of sophisticated tests specifically designed to identify a commissurotomy patient would be needed for anyone to know the operation had occurred. [Springer and Deustch, quoted in Ferguson et al. 1985, p. $503]$.

Split-brain subjects rarely exhibit abnormal behaviour outside of hyper-constrained experimental conditions. Outside of the laboratory they are generally indistinguishable from healthy subjects. It is therefore not necessary to take the results of split-brain experiments to be representative of the general human condition, or even of split-brain subjects themselves, outside of the laboratory. This consideration points toward a natural explanation of split-brain syndrome - split-brain subjects possess a unified conscious perceptual field in everyday life which is disrupted only for the duration of the experiment. Such a position has been defended by Charles Marks (1981) and Michael Tye (2003), ch. 5]. Marks argues that split-brain subjects should be taken to possess a unified consciousness because their behaviour is best described (outside experimental contexts) in terms of a single functional system. In a similar vein, Tye (2003), ch. 5] argues that the best explanation of split-brain behaviour in everyday life should lead us to conclude that consciousness only splits during the experiments. Although the specific arguments provided by each theorist for their positions differ, each is primarily motivated by the idea that the best explanation of split-brain research is that consciousness only splits during experimental circumstances.

Thomas Nagel rejects such experimental aberration accounts, and his reasons for doing so are worth quoting in full:

But the suggestion that a second mind is brought into existence only during experimental situations loses plausibility on reflection. First, it is entirely ad hoc, it proposes to explain one change in terms of another without suggesting any explanation of the second. There is nothing about the experimental situation that might be expected to produce a fundamental internal change in the patient. In fact it produces no anatomical changes and merely elicits a noteworthy set of 
symptoms. So unusual an event as a mind's popping in and out of existence would have to be explained by something more than its explanatory convenience.

But secondly, the behavioural evidence would not even be explained by this hypothesis, simply because the patient's integrated responses and their dissociated responses are not clearly separated in time. During the time of the experiments the patient is functioning largely as if he were a single individual... The two halves of his brain cooperate completely except in regard to those very special inputs that reach them separately and differently. For these reasons [the experimental aberration model] does not seem to be a real option; if two minds are operating in the experimental 'situation', they must be operating largely in harmony although partly at odds. And if there are two minds then, why can there not be two minds operating essentially in parallel the rest of the time? (Nagel 1971, p. 408, my emphasis).

If one looks closely at this quote (I have italicised the relevant parts) one can see that Nagel's argument is driven by an assumption of internalism about conscious experience. Nagel assumes that only internal brain-based differences are relevant to the structure of consciousness and so, because split-brain subjects' brains do not change between everyday life and experimental conditions, he thinks the experimental aberration account is a non-starter.

Tim Bayne has more recently objected to Tye's experimental aberration account in a similar manner to Nagel:

Is this the best explanation of split-brain behavior? One issue on which Tye is noticeably silent concerns the mechanisms by means of which the patient's phenomenology is divided and then reunified. One might well wonder how the transition between everyday and experimental contexts could (dis)unify consciousness. Why might the split-brain patient's consciousness split into two 'under certain experimental conditions'? It seems plausible to suppose both that the structure of consciousness supervenes on neural structure, and that neural structure is not altered as the patient moves into and out of experimental conditions. (Bayne 2005, p. 506).

Although neither Bayne nor Nagel directly address Marks' position, their objection straightforwardly applies to his account as well. Bayne argues that there is only one plausible way out of this bind for Tye (and Marks), and that is to accept a view upon which perceptual experience can constitutively involve external factors. Although not averse to externalist positions, ${ }^{3}$ Tye has (to the best of my knowledge) not expressed sympathy with externalism about the vehicles of consciousness. Marks, on the other hand, advocates an explicitly Fodorian account of the mind. As such, it appears as if he cannot avail of an externalist theory of conscious perception (Fodor 2009). In this paper I will defend a version of the experimental aberration account which is immune to Nagel and Bayne's objection because it allows for and accepts externalism about

\footnotetext{
${ }_{3}^{3}$ Tye is a well-known proponent of externalism about the content of representational mental states (Tye 1995; Tye 2000) 
consciousness. I will argue that the ad hoc charge only applies to internalist theories, and indeed will argue that externalist theories - theories which allow for factors external to the brain to play a constitutive role in conscious experience - in fact predict that there will be a difference in the conscious states of split-brain subjects between every day and experimental scenarios. I will argue that externalist theories can explain split-brain syndrome in a parsimonious manner and, on this basis, conclude that externalist theories should be preferred.

\section{The Nomological possibility of an externalist account of split-brain syndrome}

During the course of arguing against the coherence of partial unity accounts of consciousness, Susan Hurley provided an externalist account of split-brain syndrome [Hurley 1998, ch. 5; Hurley 2003]. ${ }^{4}$ Hurley did not intend to argue for the truth of her account. Rather, she argued for a weaker claim - that an externalist account of splitbrain syndrome is a nomological possibility. In this section I outline her argument, and explain why it allows for the theoretical possibility of an experimental aberration account of split-brain syndrome which avoids Nagel and Bayne's ad hoc objection.

Hurley begins her argument by referring to people who have been born without a corpus callosum, who are known as "acallosal patients". Acallosals appear to possess a unified conscious field, and they perform as well as healthy subjects during split-brain experiments. Consequently, the existence of acallosal patients demonstrates that it is nomologically possible for an organism to possess a unified conscious field without possessing a corpus callosum. She provides an outline of two possible explanations as to how acallosals come to possess a unified conscious field (Hurley 1998, p. 191):

1. The left and right hemispheres of acallosals are connected to one another via alternative neural pathways.

2. The left and right hemispheres of acallosals use external factors (bodily, environmental, or both) as a functional surrogate for the missing corpus callosum.

Hurley admits that the most likely explanation as to why acallosals possess a unified conscious perceptual field is explanation (1). I agree with her on this point- (1) makes best sense of why acallosals perform the same as normal subjects in split-brain experiments and it is backed up with neurophysiological evidence (Tovar-Moll et al. 2014). Although Hurley thinks that interpretation (1) provides the best explanation of acallosals, she does argue that interpretation (2) should be taken seriously as a

\footnotetext{
${ }^{4}$ It is worth noting that although Hurley herself appeared to be developing a standard extended functionalist argument for an extended mind claim [cf. Clark and Chalmers 1998; Wheeler, 2010], the argument I am going to provide is compatible with both extended and extensive mind accounts (Hutto and Myin 2013; Hutto et al. 2014). Extensive mind theories accept the idea that minds are constituted by dynamic interactions between brain, body, and world, and my argument (if understood from the perspective of an extensive mind theorist) essentially amounts to allowing for the body and/or world to take on an additional role which was once performed by the brain. Consequently, although I will adopt extended functionalist terminology in what follows, one could adopt my argument regardless of whether one preferred an extended or an extensive mind approach.
} 
nomological possibility. Her argument for this claim can be seen as a version of Andy Clark and David Chalmers' parity principle, which states that:

If, as we confront some task, a part of the world functions as a process which, were it done in the head, we would have no hesitation in recognizing as part of the cognitive process, then that part of the world is (so we claim) part of the cognitive process. (Clark and Chalmers 1998, p. 8, italics in original)

Hurley argues that, if an acallosal did unify their perceptual field via external means, we would have no reason to deny that these external factors form a constitutive part of the acallosal's perceptual field. We accept that the corpus callosum plays an important functional role in unifying an organism's conscious perceptual states. It does so because it provides the means through which the left and right hemispheres can pass information to one another. Hurley argues that if the left and right hemispheres use the environment to pass information to one another in the same manner, then we have no reason to deny that these external factors are constitutive of the organism's perceptual field. Consequently, we have no naturalistically acceptable reason to reject interpretation (2) as a possible explanation for the unity of the acallosal's perceptual field.

Hurley develops this point by referencing a comment made by the psychologist Marcel Kinsbourne:

Kinsbourne remarks that the absence of the corpus callosum is biologically trivial, since minor adjustments in orientation distribute the same information to both sides, even in the absence of cross-cuing. (Hurley 1998, p. 189)

Hurley argues that external factors could play a constitutive role in unifying conscious perception and she takes Kinsbourne's comment to provide an example of how external factors could unify conscious perception - a tilt of the head can cause information to be passed into both hemispheres, and so this head-tilt can play the same functional role as the corpus callosum (which also ensures information is passed into both hemispheres). If we accept a broadly functionalist account of perception (which most philosophers and psychologists do) then we have no reason to deny that a split-brain subject which uses this method is unifying its perceptual states and that its bodily movements play a constitutive role in this perceptual unification.

Hurley further strengthens her argument (for the nomological possibility of a conscious perceptual field unified via external factors) by introducing the hypothetical acallosal thought experiment. The hypothetical acallosal uses external factors to unify their perceptual states and they have done so since birth. Because external factors have played a constitutive role in unifying the acallosal's perceptual field since birth, Hurley assumes that only ad hoc or biologically chauvinistic considerations could motivate denying the hypothetical acallosal a unified conscious field. As such, she concludes that the hypothetical acallosal is nomologically possible. Having argued it is nomologically possible that a human could use external factors to unify their conscious perceptual states, Hurley applies her argumentative strategy to the example of splitbrain syndrome. She argues that immediately post-surgery the split-brain subject should not be seen as comparable to the hypothetical acallosal. If the split-brain subject does use external factors to pass information between its hemispheres at this stage, then they 
should be considered to possess two separate centres of consciousness (or one partially unified centre) which are working together. According to Hurley, the two hemispheres of this split-brain subject are engaged in an explicit and personal-level co-ordination of their activities and are therefore metaphysically analogous to two agents working together. However, if the split-brain subject is able to subsume their use of external factors within automatic and sub-personal mechanisms (in the same manner as the hypothetical acallosal), then Hurley argues that we would have no principled reason to deny that external factors are playing a constitutive role in unifying the split-brain subject's perceptual field.

In the next section I will provide an argument to the effect that Hurley's conjectured split-brain patient is not only possible, but in fact actual. Before doing so, I will briefly explain what I mean when I use the terms "consciousness", "personal level", and "subpersonal level" in the argument which follows. Given that I will be offering an extended functionalist argument, I define consciousness in terms of its functional properties. Ned Block is responsible for introducing the term "access consciousness" to refer to functional theories of consciousness (Block, 1995). Such theories take a given 'content' ${ }^{5}$ to be conscious if it is used to guide action, is causally efficacious in thought, and is available for verbal report (in organisms which can speak). Consequently, my argument is predicated upon an access consciousness definition of experience (Clark 2000; Cohen and Dennett 2011; O'Regan and Noë 2001). When I use the term "personal level", I should be taken to be referring to the activities of the agent as whole - their thoughts, feelings, perceptions, and so on. Personal level activities, at least as they will be understood in the present context, are typically intentional in nature and as such the agent tends to be consciously aware of having deliberately engaged in a certain course of action. My use of the term "sub-personal level", on the other hand, should be taken to refer to certain sub-parts of the embodied agent-environment system that are not properly applicable to the agent as wholeelectrical and chemical interactions within the brain, minute bodily adjustments and environmental interactions, and so on. Such actions typically occur automatically and outside of conscious awareness. Whilst my definition of consciousness is quite specific, my definition of the personal and sub-personal levels is largely ostensive and not particularly detailed. ${ }^{6}$ However, it suffices for present purposes, because I only require such a broad differentiation between the personal and sub-personal levels for my argument to go through.

\section{From possibility to actuality - The empirical evidence}

I have just outlined Susan Hurley's argument that split-brain subjects could use external factors to unify their conscious perceptual field. I am now going to provide an empirical argument for the claim that split-brain subjects do use external factors to unify their conscious perceptual field. I begin by explaining the split-brain behaviour known as

\footnotetext{
${ }^{5}$ I include scare-quotes because the 'content' in question need not necessarily be representational. Thus, my use of the concept "content" should not be understood to require acceptance of a representational account of consciousness.

${ }^{6}$ Indeed, I think Tim Bayne gets it exactly right when he writes that "the borderlands between personal-level agency and sub-personal agency [are] murky, but perhaps that is how it should be." (Bayne 2010, p. 105)
} 
cross-cueing (upon which much of my argument rests), before launching into the empirical argument proper.

\subsection{What is 'cross-cueing'?}

Cross-cueing occurs when one hemisphere attempts to pass information to the other hemisphere by using external factors - the hemisphere uses external factors to 'cue' the opposite hemisphere. Consider, as an example, three common split-brain behaviours which have been observed by Joseph Bogen (1990). In one of these behaviours, subjects will manipulate a rubber band which has been placed in their left hand in order to communicate tactile information to the left hemisphere. The left hemisphere then becomes aware that the left hand is holding a rubber band. A second common behaviour involves subjects stabbing themselves with a pencil which has been placed in their left hand. This stabbing behaviour sends tactile information to the left hemisphere, which then becomes aware that the left hand is holding a pencil. A third commonly observed form of cross-cueing is known as "verbal cross-cueing". In this form of crosscueing, the speaking left hemisphere will voice verbal instructions to the right hemisphere, which allows the latter to complete the task which has been assigned to it by the experimenter. The commonality of these behaviours is particularly striking when it is noted that "patients...only rarely if ever [meet] one another" (Bogen 1990, p. 220). Consequently, it seems as if split-brain subjects independently engage in this kind of cross-cueing behaviour.

Interestingly, cross-cueing behaviour is not restricted solely to human subjects. In a 1969 paper, Michael Gazzaniga studied the evidence for the existence of cross-cueing behaviour in monkeys. The monkeys in question were able to engage in behaviour during split-brain experiments which was incompatible with the fact they had undergone split-brain surgery. Gazzaniga suspected that these monkeys had circumvented his experimental controls by tilting their heads to pass information between their anatomically disconnected hemispheres. He tested this hypothesis by fitting a restraining device to the monkeys which restricted their ability to move their heads. Once a restraining device was fitted to the monkeys' heads, their ability to circumvent the experimental design foundered. Gazzaniga concluded that the monkeys had been using movement to pass information between their hemispheres. Moreover, he claimed that this finding was applicable to a number of other studies which had been carried out on split-brain subjects:

The cross-cuing mechanism proposed appears sufficient to explain all previous reports of ipsilateral eye-hand control in cats, monkey, and man. (Gazzaniga 1969, p. 16)

Many split-brain subjects engage spontaneously in cross-cueing behaviour. Even nonhuman animals, which presumably have little to no awareness of their peculiar situation, engage in this kind of behaviour. It is therefore plausible to think that cross-cueing is a universal behaviour which can occur without any explicit or deliberate intentional actions on behalf of a personal level agent. This provides some prima facie support for the idea that cross-cueing behaviour can be subsumed under sub-personal mechanisms. 


\subsection{Hurley's criteria}

Having explained what cross-cueing behaviour is, and having noted that it could be applicable to the sub-personal level of explanation, we can return to the argument that split-brain subjects do use external factors to unify their conscious perceptual states. Hurley claims that we can determine whether or not cross-cueing behaviour has been subsumed under one extended sub-personal system by using the following criteria (Hurley 1998, pp. 192-193):

1. If the use of external factors is accessible at the personal level and engaged in deliberately (for example, if a subject deliberately tilts their head in order to feed information to their opposite hemisphere), then this is evidence that two separate centres of consciousness are engaged in co-operation.

2. If the use of external factors is automatic and occurs without any conscious or personal level intervention, then their use can be taken to apply at the subpersonal level of explanation. For example, if a subject reflexively tilts their head without realising they have done so, then their head tilting can plausibly be construed as a sub-personal process. In such a case the splitbrain subject's consciousness can be taken to have been unified by a subpersonal system which constitutively includes external factors (specifically, one which uses parts of the body or environment as functional surrogates for the missing corpus callosum).

It has already been noted that immediately post-surgery, if the two hemispheres do pass information to one another, they are best seen as metaphysically analogous to two co-operating personal level agents. However, if we can find evidence that such co-operation between hemispheres occurs at the sub-personal level, then we can take external factors to be playing a constitutive role in unifying the split-brain subject's field of perceptual consciousness. These external factors would be fulfilling the exact same sub-personal functional role once fulfilled by the corpus callosum. Consequently, they should be accorded the status of being constitutive of perceptual experience even though they are located outside of the brain.

It might be objected, at this point, that there is no real reason to think that subpersonal cross-cueing behaviour unifies consciousness and yet personal level crosscueing does not. Susan Hurley, for example, simply assumes that this difference in levels of explanation is relevant without arguing for the point. ${ }^{7}$ The movement of crosscueing between levels of explanation is important, I believe, because it signifies the reintegration of a single centre of access consciousness. Both individual hemispheres (and the respective bodily-environmental loops emanating from them) support separate spheres of access consciousness when cross-cueing is personal level in nature because the 'contents' of each hemisphere are not integrated together- each hemisphere supports its own centre of consciousness because its 'contents' separately guide thought and action, and are available for verbal report. However, whenever cross-cueing becomes applicable at the sub-personal level this all changes. Once the cross-cueing

\footnotetext{
${ }^{7}$ My thanks to an anonymous referee for both making this observation and bringing it to my attention.
} 
mechanisms go sub-personal we arrive at one extended system which allows for a reintegration of the 'contents' of each hemisphere. Consequently, the 'contents' of each hemisphere jointly guide thought, action, and verbal report within the one overall cognitive system and, as such, support one centre of access consciousness. In short, this integrated cognitive system (hemispheres constitutively connected via external factors) supports one instance of access consciousness, whereas its component parts (disconnected hemispheres) earlier supported two such access consciousness states. ${ }^{8}$

\section{Split-brain syndrome and sensorimotor skill}

In the previous section I outlined and defended Hurley's claim that the passing of crosscueing from the personal to the sub-personal level of explanation allows for the unification of split-brain consciousness. Although Hurley does offer these criteria, she does not explain how such a transition could occur. In this section I am going to suggest that it occurs via the learning of new perceptual sensorimotor skills. Enactive and ecological theories of conscious perception take an organism's ability to perceive to be predicated on its possession and exercise of sensorimotor skills (Anderson 2014; Barrett 2011; Bruineberg and Rietveld 2014; Chemero 2016; O'Regan 2011; Noë 2004; Thompson 2007). They explain perception to be predicated on the possession and exercise of the knowledge-how required to become perceptually related to the environment. I want to suggest that we can explain how this perceptual know-how is acquired (in the case of split-brain syndrome) by applying the Dreyfus account of skill acquisition [Dreyfus 2002; Dreyfus and Dreyfus 1986/2014; cf. Dreyfus and Dreyfus 1980]. ${ }^{9}$ If we apply this account to enactive and ecological theories of conscious perception, then we will be able to provide an operationalisation of the passage of perceptual know-how from being applicable at the personal level of description to being applicable at the sub-personal level. Consequently, we could determine whether split-brain subjects do use perceptual sensorimotor skills which are partially constituted by external factors when they perceive.

\footnotetext{
${ }^{8}$ Or, alternatively, one partially unified conscious state (Lockwood 1989; Schechter 2014).

${ }^{9}$ It might be objected that the Dreyfus account is incapable of explaining the learning of perceptual sensorimotor skills, because perceptual skills are skills of an entirely different type to those the Dreyfus account is commonly used to explain (e.g. playing chess or driving a car). I am not persuaded by this objection because it is predicated on the assumption that there is some kind of important metaphysical gap between 'lower' cognitive skills (like perceiving) and 'higher' cognitive skills (like playing chess). I think enactive/ ecological accounts are better served by taking 'higher' cognitive skills to be skills of exactly the same type as 'lower' skills, with the only difference between such skills being the complexity of the socio-cultural scaffolding required to learn them [Kiverstein and Rietveld 2015; cf. Bruineberg and Rietveld 2014; Noë 2012]. On such a view of skill, there is no metaphysically problematic difference between perceptual skill and chess-playing skill because all types of skill simply involve "the individual's selective openness and responsiveness to affordances - the possibilities for action the environment offers to animals in a form of life because of the skills and abilities available within this form of life." (Kiverstein and Rietveld 2015, p. 704, emphasis in original removed). According to this kind of account, the only difference between perceptual skill and chess-playing skill is that each skill requires the agent to be 'open and responsive to' different environmental affordances. The affordances in question, however, do not differ from one another in any important metaphysical sense (e.g. affordances for 'lower' and 'higher' cognitive activity lack any metaphysically interesting differences - each affordance simply affords certain behaviour). Consequently, there is no prima-facie reason to think that the Dreyfus account of skill acquisition would be incapable of explaining the learning of perceptual skill. (My thanks to Jelle Bruineberg for helpful discussion of this point).
} 


\subsection{Applying Dreyfus' account of skill to split-brain syndrome ${ }^{10}$}

The Dreyfus account distinguishes between five stages of skill acquisition which are labelled as follows - "novice", "advanced beginner", "competence", "proficiency", and "expertise". Dreyfus" account explains skill learning as initially applicable at the personal level of explanation. When we begin to learn a new skill we engage in deliberate personal level activity. However, as the learner passes through the various stages of skill-learning, their possession and exercise of the skill comes to apply more and more at the sub-personal level of explanation. Once a skill has been mastered, the Dreyfus account takes it to be explained solely in terms of sub-personal mechanisms. Thus, stage one is thought to apply at the personal level of description whilst stage five is thought to apply wholly at the sub-personal level. This schema can therefore be used to provide a means through which Hurley's criteria can be operationalised and tested. I am going to argue that if we apply this account of skill acquisition to split-brain syndrome, we will find that split-brain subjects exhibit evidence of learning a new sensorimotor skill_ - "constitutive-cross-cueing". In exercising this skill the split-brain agent uses external factors to pass information across hemispheres, and so these external factors come to play the functional role once played by the corpus callosum. They can do so, I argue, by engaging in cross-cueing behaviours.

At the first stage of skill acquisition, which Dreyfus labels the "novice" stage, the learner is given specific information about scenarios out of context and instructed to follow specific rules in these specific scenarios. The novice chess player, for example, will be informed of the numerical value of each piece and instructed to never engage in a negative exchange. Novice learners will be unable to incorporate these instructions into the wider situational context of the activity in question, and so their knowledge is constituted by a series of autonomous, context-free, and rule-guided behaviours. For example, the novice chess player will be unable to recognise situations wherein a negative exchange would be appropriate. Rather, they will employ the rule 'never engage in a negative exchange' across the board when they play chess.

This stage would appear to best correspond to the state of the split-brain subject immediately post-surgery. If the subject does use external factors to pass information between hemispheres at this point in time, it would appear that the behaviour is engaged in deliberately. Although the subject is attempting to use external factors to replace the now-missing corpus callosum, their use of these factors would appear to be constituted by intentional and rule-guided behaviour. An example of cross-cueing which would appear to support this idea is an idiosyncratic behaviour carried out by subject N.G.:

[P] art way through test [N.G.] changed [her] manner of responding. Instead of pointing quickly with her hand, she would pause before her choices and move her hand only after a motion of her head which resulted in her pointing of her chin toward the choice subsequently pointed out by the hand. When this was recognised and she was asked not to move her head she resumed the undelayed pointing with her right hand. (Bogen 1990, p. 220)

\footnotetext{
${ }^{10}$ The cross-cueing behaviours subsequently examined have all been taken from (Bogen 1990), unless I explicitly state otherwise.
} 
N.G.'s behaviour appears to be a deliberate and personal level phenomenon because she would "pause before her choices". Furthermore, when asked to cease her behaviour N.G. was able to do so immediately (presumably, if the behaviour were automatic and sub-personal N.G. would have more trouble ceasing it). N.G. appears to have explicitly decided upon the use of this strategy in the specific context of the experiment she is subject too. Therefore, N.G.'s exercise of the skill "constitutive-cross-cueing" is best categorised at the novice stage of skill development.

The second advanced beginner stage of skill development is reached when the learner can recognise contextually defined situations and apply maxims which are specific to that particular situation. For example, the advanced beginner will be capable of determining when an opponent's King's defence is weak and will be capable of applying the maxim 'attack a weakly defended King' in light of their determination. Whether or not a King's defence is weak is something which can only be determined in the context of a specific game, and so the advanced beginner's decision to attack the King is based on situation-specific knowledge. The advanced beginner has moved beyond the novice stage because they are now capable of recognising context-specific situations and responding to them in an appropriate manner.

Split-brain patient R.M. shows signs of being at the advanced beginner stage of learning the skill "constitutive-cross-cueing". R.M. exhibited a number of (largely ineffective) cross-cueing behaviours when undergoing tests four months after surgery ${ }^{11}$ :

When a pencil was placed in his left hand he held it appropriately but could not name it. It was then put into his right hand and he said, "a pencil." When a watch was put in his left hand, he said it was a "pencil" even when, with his left hand, he was holding the watch up to his left ear. A paper clip was put in his hand and he could not tell what it was; but when he put it in his right hand he immediately identified it. A pipe in the left hand was put into his mouth in an appropriate way; but it was called a "pencil" even after the bit was between his teeth. When an ashtray was put into his left hand he struck the table with it; it made a distinctive sound and he immediately told me what it was. When a pair of glasses was put in his hand, he could not name what he was holding until he tried to put them on. A handkerchief was put in his left hand; his left hand immediately put it into his left hip pocket...but he could not say what it was. (Bogen 1990, pp. 219-220).

R.M. is attempting to engage in cross-cueing behaviour and he does appear to recognise that, in the context of experimental situations, it is a good idea to exercise the skill "constitutive-cross-cueing". However, R.M. is not very proficient in this skill and so his attempts to exercise it are largely unsuccessful.

At stage three of Dreyfus' hierarchy the learner is labelled "competent". Competent learners possess the ability to discern a number of task-relevant situations and they are capable of focusing on one task to the exclusion of the others. They will be able to act in accordance with the actions appropriate for that particular task whilst ignoring the actions which could be undertaken were they to be engaged in a different task. For

\footnotetext{
${ }^{11}$ I quote these behaviours at length because I will be returning to them shortly, in the context of discussing a different split-brain subject.
} 
example, the competent chess player will possess the ability to discern both that their opponent has a weak Kingside defence and that they themselves have a weak pawn structure. They will be capable of focusing and acting upon one of these situations to the exclusion of the other. If they decide to attack the opponent's King and that attack further weakens their pawn structure, they will be able to ignore the guideline 'rectify a weak pawn structure' in order to succeed in the task of attacking the opponent's King. Competent learners follow situation-specific maxims as opposed to situationindependent rules. Instead of prescribing specific actions for the completion of a given task, such situation-specific maxims instead prescribe general guidelines for contextdependent situations. The competent chess player's attack on the opponent's King will be guided by the 'attacking the King' maxim, and the moves they make will be determined by the context of the particular state of the game. Their moves will not be guided by rules which prescribe specific moves which should be made when attacking the King.

The competence stage of split-brain subjects learning the skill "constitutive-crosscueing" seems to best describe a set of behaviours observed by Kingstone and Gazzaniga (1995). The word "o'clock" was flashed to the subject's left hemisphere whilst the word "ten" was flashed to its right hemisphere. When the split-brain subject was asked to draw what they had seen, they (surprisingly) drew a picture of a clock which was showing the time was ten o'clock. Kingstone and Gazzaniga performed a series of further experiments on this subject. They concluded that the subject had been able to circumvent the experimental conditions by allowing each hemisphere to control the subject's left hand. The left hemisphere was initially given control of the left hand and it drew a clock. The right hemisphere was then given control of the left hand, and it drew the hands of the clock to indicate ten o'clock. Interestingly, Kingstone and Gazzaniga commented that "the only integration to be found here occurred 'on the sheet of paper in the drawing itself'" (Kingstone and Gazzaniga 1995, p. 324). If my thesis is correct, such external factors do indeed play a constitutive role in integrating the subject's perceptual field.

Unfortunately, Kingstone and Gazzaniga did not investigate the extent to which the subject's co-ordination of hemispheric control of the hands was a deliberate and personal level decision or an automatic and sub-personal behaviour. So I can only provide a speculative explanation of the behaviour. That said, the behaviour is consistent with the subject having become used to applying the skill "constitutive-crosscueing" even during experimental conditions. The subject's behaviour was novel in the context of split-brain experiments, so there is reason to believe the subject is competent at the skill. My main reason for taking the subject to be only competent at the skill (as opposed to more advanced) is that the subject's integrative behaviour was quite unimaginative. For example, when shown the words "hot" and "dog" the subject used the same technique (of switching hemispheric control of the hand) to draw a dog panting in heat. It would be more natural to interpret these words to refer to a piece of meat in a bun, and so a drawing of a sausage in a bun would be more appropriate. This indicates that the subject is not completely practised in applying the skill "constitutive-cross-cueing" during split-brain experiments. They are capable of applying the maxim 'switch-hemispheric-control-of-hands' during split-brain experiments. However, they are not particularly skilled at applying the maxim across different situations within the experiments. 
Subjects who have reached the fourth stage of adaption are labelled as "proficient". Proficient performers possess the ability to intuitively 'see' salient aspects of a given situation. However, they must still engage in explicit deliberation of maxims in order to determine the best course of action to undertake. A proficient chess player, for example, will be able to instinctively 'see' that the best course of action to take would be to mount an attack on the opponent's King. They will still, however, need to plan this attack by considering the specific moves they should make. Split-brain subject L.B. appears to be at the proficient stage of learning the skill "constitutive-cross-cueing". Consider the following behaviour, which he carried out during a split-brain experiment:

After a picture of a tree appeared in the left hemi-field, his hands formed a triangle, and he then said 'teepee'. (Bogen 1990, p. 220)

L.B. appears to be well-practiced in engaging in split-brain experiments, to the point where he can 'see' from the context of the situation that cross-cueing would be appropriate. However, he is still using rather obvious bodily cues - he makes a rather noticeable triangular shape with his hands, as opposed to using the more subtle embodied cues and perceptual behaviours ${ }^{12}$ which proliferate in extremely experienced split-brain subjects (Gazzaniga 2013) — and this makes it appear as if he must still explicitly deliberate on what action to perform. In other words, he can 'see' he is in a split-brain experiment but he must still make a personal level decision to engage in a specific cross-cueing behaviour. Having said this, such behaviour has only been observed in L.B. and so it seems he is at a particularly advanced stage of applying the skill "“constitutive-cross-cueing”. I therefore think the label proficient is most appropriate for L.B.

The final and most advanced stage of skill learning is labelled "expertise". Experts simply instinctively 'see' the specifics of their situation, and they intuitively 'know' how best to respond to the situation in question. Experts exercise skills absorbedlythey perform automatically and lack any awareness of what they are doing. They do not need to think about what they are doing. Indeed, (according to Dreyfus) thinking will actually have a negative effect on the actor's performance of the skill. Dreyfus argues that the best way to explain the behaviour of experts is to understand it to be wholly automatic, sub-personal, and to occur without thought. Rather than thinking about what they are doing, experts simply allow their bodies to perform the activity.

Split-brain subject C.C. appears to have achieved expertise in the skill "constitutivecross-cueing". C.C. was asked to perform the same tasks as subject R.M. (quoted in detail earlier). However, he was much more effective in his execution of the tasks. C.C. was often observed to engage in non-verbal cross-cueing behaviours "which sometimes led to the correct answer and sometimes to an answer which was related but not correct" (Bogen 1990, p. 219). ${ }^{13}$ As Bogen notes, "it is quite instructive how an individual with a verbal IQ under 70 (65 at this time) can use minimal sensory cues to identify objects which are familiar to him." [ibid, p. 219]. C.C. is not particularly well-equipped (cognitively) to actively decide to

\footnotetext{
${ }^{12}$ I use the phrase "perceptual behaviour" as an umbrella term to refer to movements which are carried out in order to pass information across hemispheres. For example, head movements, eye saccades, tactile crosscommunication (e.g. stabbing hand with pen), and so on, would all count as perceptual behaviours.

${ }^{13}$ His inability to correctly name some objects could be partially explained by his having a low IQ whilst being tested. For example, C.C. was unable to name a pine-cone even when exposed to one outside of test conditions.
} 
engage in cross-cueing. He is not cognitively well-equipped to successfully perform such behaviours. Finally, he does not appear to be deliberately engaged in their execution. Given these points, there is some reason to believe that C.C.'s cross-cueing behaviours are automatically deployed and so best described as applying to the sub-personal level of description. This is an attractive explanation of C.C.'s behaviour because C.C. was being tested eight years after surgery. We can therefore explain the difference between C.C.'s performance, and the performance of R.M. (who was tested only four months after surgery), by arguing that C.C. has achieved mastery of the sensorimotor skill "constitutive-crosscueing". C.C. excels in the skill "constitutive-cross-cueing" because he has practiced it for eight years. He can thereby be labelled an expert of this skill.

Indeed, one could go further here and argue that the general behaviour of split-brain subjects in everyday life is best described in terms of their possessing expertise in the skill "constitutive-cross-cueing". Split-brain subjects are virtually indistinguishable from healthy controls in everyday life. Once they have adapted to the absence of the corpus callosum they primarily engage in aberrant behaviour only during experiments (however, even during experiments they still occasionally exercise the skill "constitutive-cross-cueing", as we have seen). Split-brain subjects appear to deploy the skill "constitutive-cross-cueing" automatically, and the fact they are not aware that they do so indicates that this skill is being deployed absorbedly. Consequently, these subjects appear to display expertise in this skill. If subjects are experts at performing this skill, then it is best described as applying at the sub-personal level. The external factors used by the split-brain subject should therefore be considered to be constitutive of experience - they have replaced the corpus callosum and now play the functional role of integrating the anatomically split hemispheres and so enabling a singular centre of access consciousness.

\subsection{Does recent empirical evidence require we revise the standard account of split-brain syndrome?}

Pinto et al. have recently published a paper which prima-facie appears to conflict with the standard understanding of split-brain syndrome outlined in this paper, and the empirical work upon which this understanding has been based (Fig.1, Pinto et al.

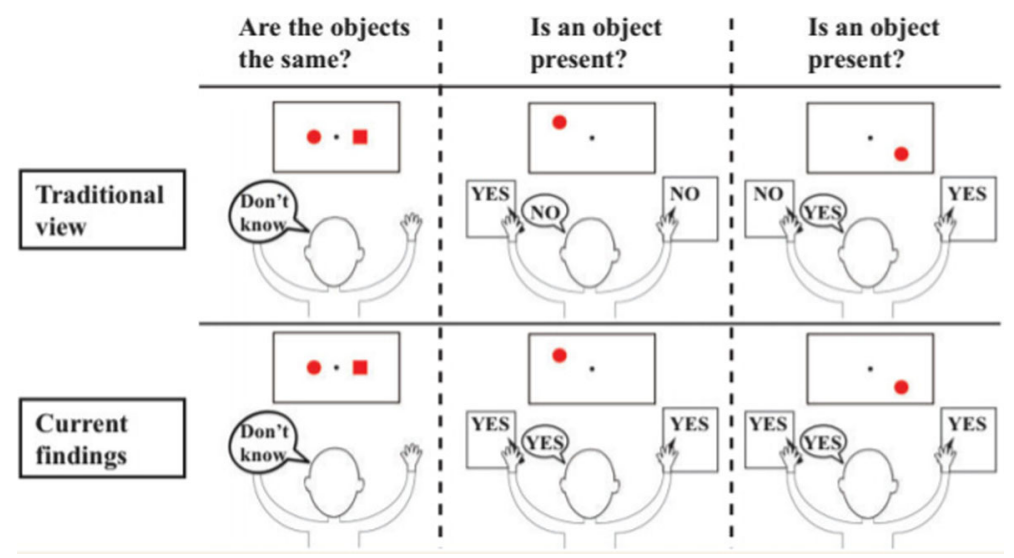

Fig. 1 The standard account of split-brain syndrome and Pinto et al.'s findings 
2017). As previously explained, it has commonly been thought that if stimuli are localised to the left and right hemispheres of a split-brain subject, each hemisphere will engage in autonomously controlled and goal-directed cognitive behaviour in response to the particular stimulus that hemisphere has been exposed to. Furthermore, each hemisphere will do so whilst being completely unaware of the information 'contained within' and/or acted upon by the opposite hemisphere. However, when Pinto et al. subjected split-brain subjects to the same kinds of experimental tests outlined above, their results differed in extremely important ways from that of previous empirical work. Pinto et al. helpfully provide the following diagram which summarises their findings:

In short, although Pinto et al. replicated the finding that split-brain subjects cannot compare stimuli which have been localised to different hemispheres (the first box), they found that subjects could correctly answer questions about a given stimuli regardless of which hemisphere was in control of answering the question and which hemisphere the stimulus in question was localised to (boxes two and three). According to Pinto et al. these experimental results show that whilst perceptual information is localised to a given hemisphere during the split-brain experiment, cognitive access is not localised to a given hemisphere. Thus, it is not true that each hemisphere is cognitively unaware of the stimulus presented to and/or acted upon by the opposite hemisphere.

If one adopts an internalist approach toward split-brain syndrome, these results are indeed peculiar. The brains of the subjects tested by Pinto et al. have previously been mapped and it has been confirmed that their hemispheres were fully split during surgery and that no new anatomical inter-hemispheric connections have subsequently developed in their brains. As such, if one adopts an internalist perspective, this empirical work appears to require one of two conclusions:

1. Most, if not all, of the previous experimental work on split-brain syndrome (which spans decades) was fundamentally misguided, misinterpreted, and/or carried out incorrectly.

2. Both the previous experimental work carried out on split-brain syndrome and the empirical work reported in the Pinto et al. paper is of good standing. As such, something extremely mysterious has occurred.

Of course, neither (1) nor (2) is appealing for the empirically minded philosopher or psychologist. However, if one adopts the externalist approach outlined in this paper, then a third option becomes available:

3. Both the previous experimental work carried out on split-brain syndrome and the empirical work reported in Pinto et al.'s paper is of good standing. The reason the more recent results diverge from earlier reported work is that the subjects in question have become more adept at exercising the perceptual skill 'constitutivecross-cueing'.

By adopting an externalist account, one can provide a non-mysterious explanation as to why Pinto et al. derived the results that they did without calling into question the empirical credentials of virtually all the work previously carried out on split-brain syndrome. Indeed, the account sketched in this paper arguably predicts these recent 
empirical findings. The subjects reported on in Pinto et al. had each undergone splitbrain surgery some time ago and each had plenty of experience participating in splitbrain experiments. It is therefore quite likely that these results occurred because subjects have almost completely mastered the skill 'constitutive-cross-cueing', to the extent that it can be exhibited even during experimental conditions.

Pinto et al. do actually countenance the possibility that the results they report could have been due to cross-cueing. However, they reject this possibility for four reasons: (1) cross-cueing mechanisms are incapable of transmitting the amount of information possessed by subjects; (2) given that perceptual information about localised stimuli was not possessed by both hemispheres, it is unlikely that subjects possess knowledge of localised stimuli due to cross-cueing (if they did, then why was the perceptual information not transferred across hemispheres?); (3) the experiments were specifically designed so that cross-cueing could not occur and no cross-cueing was observed; and, (4) patient responses occurred too quickly for them to be explained by cross-cueing. (Pinto et al. 2017, p. 1236).

Pinto et al. defend point (1) with reference to a paper by Baynes et al. (1995). However, although this paper does appear to show that the ability to transfer information via cross-cueing mechanisms is limited, Baynes et al. specifically note that the subject under study in this particular paper is constantly improving his skill at using cross-cueing mechanisms within split-brain experiments, such that his performance in these experiments improves over time (Baynes et al. 1995, p. 1232, p. 1236, \& p.1240). Thus, it is not only the case that Pinto et al. can't rule out the possibility that crosscueing strategies improve over time. In fact, the paper they reference to show that crosscueing strategies can transfer only limited amounts of information actually argues for the claim that subjects exhibit improved performances on experimental tasks because cross-cueing mechanisms improve over time. Therefore, it specifically allows for the conclusion that the amount of information passed between hemispheres can increase as cross-cueing abilities improve. Although point two does show that the subjects have not been able to use cross-cueing to pass all information across hemispheres, it does not therefore show that no cross-cueing occurs. For example, consider that the results upon which this point is predicated do not differ substantially from those reported by Kingstone and Gazzaniga which were discussed earlier in this paper. That crosscueing is not perfectly executed in a given situation does not thereby show that no cross-cueing whatsoever has occurred. Point three likewise does not show that crosscueing does not occur, because there are plenty of examples wherein cross-cueing occurs in spite of experimental set-ups designed to remove its possibility, and it often takes further experimental work to find out the exact nature of a given cross-cueing strategy in a given experiment (cf. Gazzaniga 1969, 2013). Finally, it is not clear that the speed of patient response shows that cross-cueing could not have occurred. If subjects have learnt to use embodied or environmental mechanisms to play a constitutive role in unifying their conscious perceptual fields, then there is no principled reason to suspect that such external mechanisms would be any slower at passing information between hemispheres than the corpus callosum. ${ }^{14}$

\footnotetext{
${ }^{14}$ Note, I do not here take myself to have refuted Pinto et al.'s position on cross-cueing. Rather, I take myself only to have shown that more needs to be said on each of these points in order to rule out a cross-cueing based explanation of split-brain syndrome such as the one outlined in this paper.
} 
Interestingly, Pinto et al. do note that the time which had passed since the surgery has occurred could have played a role in their experimental findings. They suggest that perhaps "patients somehow develop mechanisms or even structural connections to re-integrate information across the hemispheres" (Pinto et al. 2017, p. 1236). This is precisely what I think has occurred, and the forgoing argument suggests a possible way in which it can be tested. It is unlikely that patient's brains would have developed new connections - they are too old - but it is quite possible they could have developed a novel extended sub-personal system in response to having their corpus-callosum severed. Thus, rather than being problematic for the argument presented in this paper, these recent experimental results would appear to in fact support it.

\section{3 'Siamese twin' objection ${ }^{15}$}

Another possible way to object to my argument would be to invoke the "Siamese Twin Objection". According to this objection, if my argument is correct it may turn out to have too strong a conclusion - two human agents who engage in extremely closely integrated behaviour could come to possess a unified field of perceptual consciousness. Michael Lockwood raised this objection by using the example of Siamese twins (Lockwood 1994) and, interestingly, this counter-example appears to be somewhat of a reality: (Fig. 2).

Shivanath and Sharam can navigate their environment with relative ease and are capable of successfully co-ordinating their actions to complete everyday mundane behaviours (such as showering and dressing). Consequently, they could (presumably) co-ordinate their behaviour in such a way that their brains received sensory stimulation which accorded with Shivanath-and-Sharam-specific sensorimotor contingencies. If this is possible, then the argument proffered in this paper may appear to require that Shivanath and Sharam could come to possess a unified perceptual field in exactly the same manner as split-brain subjects. Furthermore, by a similar logic, my argument could also appear to license the existence of group consciousness - if groups of agents could co-ordinate their perceptual actions in a tightly integrated manner, then the individual members of the group could unify their conscious states such that there is 'something it is like' for the group (as an entity) to perceive.

In many ways, this objection is analogous to those which surfaced in the immediate aftermath of the original publication of the extended mind argument (Clark and Chalmers 1998). It was commonly objected that the extended mind had unpalatable consequences, and as such should be rejected. For example, the argument appeared to entail that the entire contents of the internet could count as part of an individual agent's memory, or that groups of agents (such as institutions) could themselves count as being minded entities. There are roughly three stances which could have been taken in response to such objections: deny the more extreme consequences by tightening up one's definition of when minds can reasonably be said to extend; accept these extreme conclusions as a surprising but sound consequence of a valid argument; or, leave the possibility of such conclusions on the table as a theoretical possibility, but as one which requires further argumentative work to arrive at. I think that a similar set of stances is available when defending my argument from the Siamese-twin objection.

\footnotetext{
${ }^{15}$ My thanks to an annonymous reviewer for raising a number of issues with my original response to this objection, and to Roger Clarke and Joe Morrison for helpful discussion about how my original response could be modified and improved.
} 


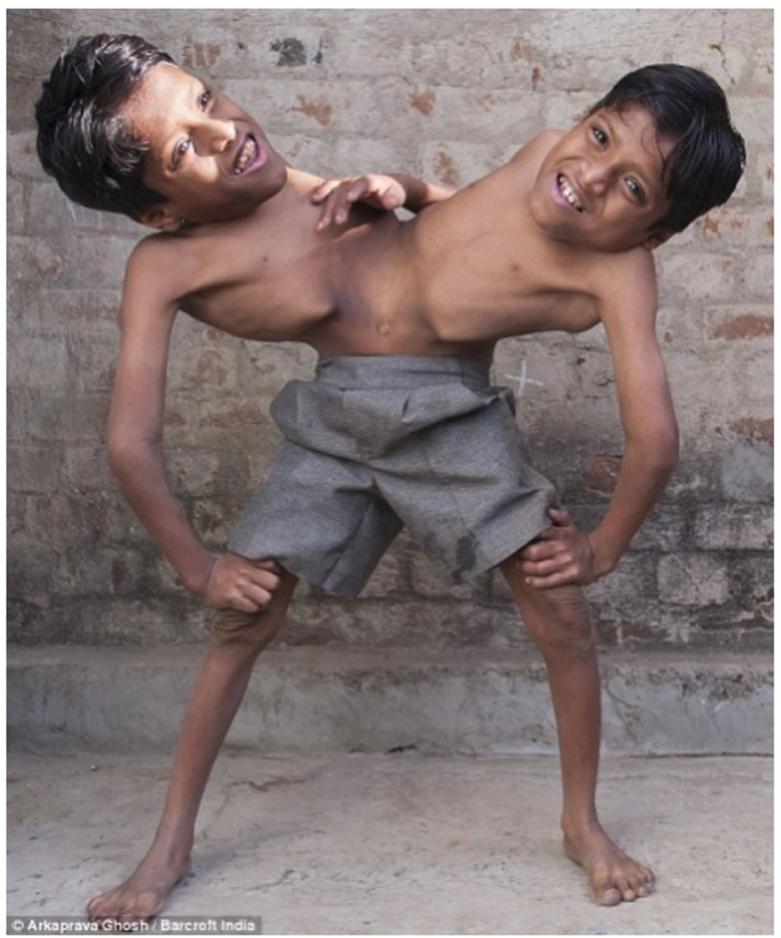

Fig. 2 Shivanath and Sharam [Ghosh, 2017]

One could outright reject the possibility of group consciousness by providing some further conditions as to when consciousness can occur, and explaining why these conditions are met in split-brain syndrome but not in Siamese twins or groups of agents. Andy Clark, for example, has argued against the possibility of consciousness extending beyond the brain by claiming that only brains can support the extremely precise, time-sensitive information-processing required for consciousness [2009]. One could provide a similar argument in the context of my account of split-brain subjects (of course, doing so requires diverging from Clark's position because he does not think consciousness can extend beyond the brain ${ }^{16}$ ). Michael Anderson has recently provided an empirically detailed account of how brains co-ordinate their own activities with bodily and environmental factors in order to efficiently spread cognitive load and successfully engage in goal-directed activities (Anderson 2014), and this account has been applied to and used to explain consciousness (Downey 2016). Anderson's account may require that parts of the brain need to physically be in close proximity to successfully co-ordinate activity, such that even the relatively short distance between the brains of Siamese-twins rules out the possibility of their forming a single extended sub-personal system. ${ }^{17}$ Of course, the brains of individuals within a group are physically removed to an even greater extent, so such an account of

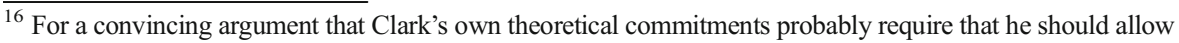
for extended consciousness, see (Loughlin 2013).

${ }^{17}$ It is worth remembering, in this regard, that only the hemispheres of split-brain patients are anatomically isolated. Sub-cortical connections are not affected by the procedure, with the result that both hemispheres share the same blood supply, sleep-wake cycle, and so on.
} 
consciousness would likewise rule out the possibility of the group unifying their states of consciousness through the formation of one extended sub-personal perceptual system.

Alternatively, one could simply accept the possibility that Siamese-twins and groups of agents could unify their consciousness in exactly the same manner that I have argued split-brain subjects do. Whilst this would be a surprising and counter-intuitive conclusion, it is not clear that it should be rejected solely on that basis. Just as the extended mind is (arguably) logically entailed if one accepts a functionalist account of mind (Wheeler 2010), it could turn out that the existence of group consciousness is logically entailed if one accepts a functionalist account of consciousness (Schwitzgebel 2015). Thus, the existence of group consciousness may simply be a consequence of a sound and valid argument.

At present, I think it is best to conclude that the argument developed here appears to allow for the possibility of group consciousness, but that much more work needs to be done before this question can be decided either positively or negatively. After all, providing an argument for or against group consciousness (in the present context) requires that one provide specific details about specific examples and explain why they are relevantly like the split-brain case. For example, one would have to show that Shivanath and Sharam exhibit the same kinds of cross-cueing behaviours and relevantly similar group perceptual behaviour as split-brain subjects before concluding that they possess a singular group perceptual consciousness. Consequently, resolving this possibility in any direction requires much further work, and so I suggest that the Siamese-twin counterexample be left open as an avenue for future research.

\section{The (strong) empirical credentials of the externalist experimental aberration account}

I want to finish this paper by briefly highlighting the empirical strengths of the externalist account of split-brain syndrome outlined and defended in this paper. These are two-fold: (1) externalist accounts make essential reference to the key explanatory posits used to explain split-brain syndrome in this paper- externalism about perceptual consciousness and sensorimotor skill - independently of split-brain syndrome, and so rather than providing an ad hoc explanation of split-brain experiments arguably predict their results; (2) the externalist account makes a number of predictions which can be empirically tested, and so its truth or falsity can be determined via empirical means. Consequently, the account provides a parsimonious explanation of split-brain syndrome which is empirically well-grounded.

\subsection{Ecological/enactive accounts and the experimental aberration interpretation}

The reader will recall that the experimental aberration model takes the bizarre behaviour of split-brain subjects to be explained by the context of the experiment itself. Splitbrain subjects are thought to possess a unified perceptual field in everyday life and this field becomes split only during the course of split-brain experiments. The most common objection to this account of split-brain syndrome is that it is ad hoc- there is no real, principled reason to think that engaging in split-brain experiments would 
cause a split in conscious experience. The ad hoc objection is rooted in an internalist view of consciousness, which assumes consciousness to be brain-bound. The brain's anatomical or functional structure is thought to be constitutive of conscious experience, and engaging in split-brain experiments does nothing to change the anatomical or functional structure of the brain. Therefore, there is no reason to think split-brain experiments would cause a change of structure in conscious experience. As such, internalists conclude that split-brain experiments reveal a fact about the conscious experience of split-brain subjects which is true of them even outside experimental conditions [cf. §2, this paper].

Externalist accounts of consciousness, however, can provide a principled response to the ad hoc objection. In the case of enactive and ecological theories (e.g. (Anderson 2014; Chemero 2009; Gibson 1979; Hutto and Myin 2013; Noë 2004; Thompson 2007; Varela et al. 1991)), the response would go as follows - splitbrain experiments negate the subject's ability to exercise the skill "constitutivecross-cueing" because they block off the subject's ability to use external factors to unify their perceptual states. Given that these external factors act as a functional replacement for the corpus callosum, split-brain experiments are effectively equivalent to the subject under-going a second (temporary) split-brain procedure. Consequently, it should be expected that split-brain experiments would have the results that they do. This is a particularly strong response to the ad hoc objection because it falls out naturally from enactive/ecological theories. Such accounts already take external factors to be constitutive of perception, and they already understand perception to occur when an organism possesses and exercises sensorimotor know-how, prior to consideration of split-brain syndrome. Each of these posits plays a crucial role in the argument for the claim that split-brain subjects learn the skill "constitutive-cross-cueing" after under-going split-brain surgery. Given that both externalism about perceptual consciousness and sensorimotor skill are invoked by enactive/ecological theories independently of split-brain syndrome, it therefore cannot be objected that such theories invoke these posits in order to accommodate this phenomenon. Indeed, rather than having to gerrymander their accounts of conscious perception in order to deal with split-brain syndrome, enactive/ecological accounts arguably predict the phenomenon- unlike acallosal subjects, split-brain subjects' brains lack the ability to develop new neural connections because they are too old. Consequently, it is likely that their brains will use external factors in place of the severed corpus callosum [cf. Anderson 2014; Clark, 1997; 2008].

\subsection{Empirical predictions}

I have argued that accepting an externalist view of consciousness provides one with the theoretical tools necessary to provide a parsimonious explanation of split-brain syndrome. I applied enactive/ecological accounts to this phenomenon and argued that split-brain subjects behave normally in everyday life because they exercise the skill "constitutive-cross-cueing". I suggested that applying the Dreyfus' theory of skill learning to this account could provide a means of operationalising the learning of this new sensorimotor skill. This is a novel argument, and no-one has investigated split-brain syndrome with this hypothesis 
in mind. Therefore, the empirical examples I used to support my account were necessarily speculative. The argument itself is, however, an empirical one. I can think of three ways that the account could be tested:

1. I have made the empirical claim that, over the course of learning the skill "constitutive-cross-cueing", personal level co-operative behaviour eventually becomes subsumed into the sub-personal level. There is some evidence that brain activity does decrease when skill learning advances. For example, Gobel et al. (2011) have noted that brain activity decreases as subjects adapt to the learning of a novel motor skill. One could therefore apply a version of Gobel et al.'s experimental protocol - which involved subjecting participants to functional magnetic resonance imaging (fMRI) scans whilst they performed a task requiring precise motor control - to my own hypothesis (about the split-brain subject's learning of the skill "constitutive-cross-cueing"). In practice it may be difficult to test my claim in this manner. Participants must keep their heads still during fMRI scans, but if they remain still they will be unable to engage in many of the kinds of crosscueing strategies that allow for constitutive cross-cueing. ${ }^{18}$ However, perhaps there are ways in which this limitation could be overcome such that we could test my claim using a version of Gobel et al.'s protocol (e.g. we could focus on testing subjects who make extensive use of specifically tactile cross-cueing methods).

2. My argument could also be tested by focusing on the perceptual behaviour of splitbrain subjects (head movement, eye movements, and so on). If my argument is correct, split-brain subjects should exhibit noticeably different patterns of perceptual behaviour as they adapt to their newfound sensorimotor skill. This difference is predicted because, if external factors are used to pass information between hemispheres, then the subject must be using its perceptual capacities to make use of external factors in this manner. There should therefore be a noticeable difference in the perceptual behaviour of split-brain subjects - most prominently, in their visual behaviour (e.g. the rate at which they saccade their eyes, where exactly they look and for how much time, and so on) - after they have undergone the split-brain procedure.

One could test this hypothesis by recording the behaviour of subjects during split-brain experiments and thereafter tracking the rates at which they engage in various perceptual behaviours (moving their head, shifting their gaze, and so on). Additionally, one could equip subjects with a mobile eye-tracker and record their eye movements as they engage in experiments. A marked difference between perceptual behaviours immediately post-surgery and thereafter would be required for my hypothesis to be empirically confirmed. This experiment could feasibly be performed on macaque monkeys. ${ }^{19}$

3. Finally, my account relies on the empirical adequacy of both enactive/ecological theories of conscious perception and Dreyfus' account of skill acquisition. If either of these accounts are found to be empirically inadequate, then so too will my explanation of split-brain syndrome.

\footnotetext{
${ }^{18} \mathrm{My}$ thanks to an anonymous reviewer for raising this point and bringing it to my attention.

19 Though I am not sure I could condone its being carried out (for ethical reasons).
} 


\section{Conclusion}

In this paper I have argued that, by adopting an externalist account of perceptual consciousness, one can provide a parsimonious account of split-brain syndrome. I argued that split-brain subjects can be understood to unify their conscious perceptual fields by learning a new sensorimotor skill — "constitutive-cross-cueing" — and that consciousness comes to be split only during experimental circumstances because the experimental controls block exhibition of this skill. I then provided an argument for this claim and defended it against potential counter-examples. Finally, I highlighted the empirical strengths of my position. The existence of split-brain syndrome has long mystified theorists working in the areas of philosophy and cognitive science. I have argued that externalist accounts can, however, provide a straightforward, independently motivated, and empirically plausible account of split-brain syndrome which strips it of its mystery. I conclude that, on this basis, we have strong reasons to accept externalist accounts of consciousness.

Acknowledgments I would like to thank Sarah Sawyer and Chris Mole for extremely helpful comments on, and discussion of, this paper. I would also like to thank two annonymous reviewers from this journal for extremely helpful constructive feedback. This paper was presented at a Graduate Work-In-Progress Seminar at the University of British Columbia, and I would like to thank the audience of this seminar for interesting comments and discussion.

Open Access This article is distributed under the terms of the Creative Commons Attribution 4.0 International License (http://creativecommons.org/licenses/by/4.0/), which permits unrestricted use, distribution, and reproduction in any medium, provided you give appropriate credit to the original author(s) and the source, provide a link to the Creative Commons license, and indicate if changes were made.

\section{References}

Anderson, M. (2014). After phrenology: Neural reuse and the interactive brain. Cambridge: MIT Press.

Barrett, L. (2011). Beyond the brain: How body and environment shape animal and human minds. Oxford: Princeton University Press.

Bayne, T. (2005). Divided Brains \& Unified Phenomenology: A review essay on Micheal Tye's "consciousness and persons". Philosophical Psychology, 18(4), 495-512.

Bayne, T. (2010). The Unity of consciousness. Oxford: Oxford University Press.

Baynes, K., Wessinger, C., Fendrich, R., \& Gazzaniga, M. (1995). The emergence of the capacity to name left visual field stimuli in a Callosotomy patient: Implications for functional plasticity. Neuropsychologia, 33(10), 1225-1242.

Block, N. (1995). On a confusion about a function of consciousness. Behavioral and Brain Sciences, 18(2), 227-247.

Bogen, J. (1990). Mental duality in the anatomically intact cerebrum. In C. Trevarthen (Ed.), Brain Circuits and Functions of Mind. Cambridge: Cambridge University Press.

Bruineberg, J., \& Rietveld, E. (2014). Self-organization, free energy minimization, and optimal grip on a field of affordances. Frontiers in Human Neuroscience, 8, 599.

Chemero, A. (2009). Radical embodied cognitive science. Cambridge: MIT Press.

Chemero, A. (2016). Sensorimotor empathy. Journal of Consciousness Studies, 23(5-6), 138-152.

Clark, A. (1997). Being there: Putting brain, body, and world together again. Cambridge: MIT Press.

Clark, A. (2008). Supersizing the mind: Embodiment, action, and cognitive extension. Oxford: Oxford University Press.

Clark, A. (2000). A case where access implies qualia? Analysis, 60(1), 30-37.

Clark, A., \& Chalmers, D. (1998). The extended mind. Analysis, 58, 10-23. 
Cohen, M., \& Dennett, D. (2011). Consciousness cannot be separated from function. Trends in Cognitive Sciences, 8, 358-364.

Downey, A. (2016). Radical sensorimotor enactivism and predictive processing. In T. Metzinger \& W. Wiese (Eds.), Philosophy and Predictive Processing. Frankfurt am Main: OPEN-MIND.

Dreyfus, H. (2002). A phenomenology of skill acquisition as the basis for a Merleau-Pontian non-representationalist cognitive science. Vatican City, Rome: Proceedings of the International Conference 'Foundations and the Ontological Quest'.

Dreyfus, H. \& Dreyfus, S. (1980). A five-stage model of the mental activities involved in directed skill acquisition. Operations Research Centre. University of California, Berkeley.

Dreyfus, H. \& Dreyfus, S. (1986/2014). From Socrates to experts: The limits of calculative rationality. In Wrathall (ed.) Skillful Coping: Essays on the phenomenology of everyday action and perception. Oxford: Oxford University Press.

Ferguson, S., Rayport, M., \& Corrie, W. (1985). Neuropsychiatric Observations on Behavioral Consequences of Corpus Callosum Section for Seizure Control. In A. Reeves, \& D. Roberts, Epilepsy and the Corpus Callosum (pp. 501-514). Springer.

Fodor, J. (2009). Where is my mind? London Review of Books, 13-15.

Gazzaniga, M. (1969). Cross-cuing mechanisms and lpsilateral eye-hand control in split-brain monkeys. Experimental Neurology, 11-17.

Gazzaniga, M. (2000). Cerebral specialization and interhemispheric communication: Does the corpus callosum enable the human condition? Brain, 123, 1293-1326.

Gazzaniga, M. (2013). Shifting gears: Seeking new approaches for mind/brain mechanisms. Annual Review of Psychology, 64, 1-20.

Ghosh, A. (2017). (http://www.khaskhabar.com/images/picture_image/1397197526-conjoind-twins-10.jpg). Shivanath and Sharam. India.

Gibson, J. J. (1979). The ecological approach to visual perception. Boston: Houghton-Mifflin.

Gobel, E., Parrish, T., \& Reberb, P. (2011). Neural correlates of skill acquisition: Decreased cortical activity during a serial interception sequence learning task. NeuroImage, 58(4), 1150-1157.

Hurley, S. (1998). Consciousness in action. Cambridge: Harvard University Press.

Hurley, S. (2003). Action and the unity of consciousness, and vehicle externalism. In A. Cleeremans (Ed.), The Unity of Consciousness: Binding, Integration, and Dissociation (p. Ch. 3). New York: Oxford University Press.

Hutto, D., \& Myin, E. (2013). Radicalizing Enactivism: Basic minds without content. Cambridge: MIT Press.

Hutto, D., Kirchoff, M., \& Myin, E. (2014). Extensive Enactivism: Why keep it all in? Frontiers in Human Neuroscience. https://doi.org/10.3389/fnhum.2014.00706.

Kingstone, A., \& Gazzaniga, M. (1995). Subcortical transfer of higher order information: More illusory than real? Neuropsychology, 9, 321-328.

Kiverstein, J., \& Rietveld, E. (2015). The primacy of skilled intentionality: On Hutto \& Satne's the natural origins of content. Philosophia, 43(3), 701-721.

Lockwood, M. (1989). Mind, brain and the quantum. Oxford: Blackwell Publishers.

Lockwood, M. (1994). Issues of unity and objectivity. In C. Peacocke (Ed.), Objectivity, Simulation, and the Unity of Consciousness (pp. 89-95). Oxford: Oxford University Press.

Loughlin, V. (2013). Sketch this: Extended mind and consciousness extension. Phenomenology and the Cognitive Sciences, 12(1), 41-50.

Marks, C. (1981). Commissurotomy, consciousness, and the Unity of mind. Cambridge: Bradford Books (MIT Press).

Nagel, T. (1971). Brain bisection and the Unity of consciousness. Synthese, 396-413.

Noë, A. (2004). Action in perception. Cambridge: MIT Press.

Noë, A. (2012). Varieties of presence. Cambridge, MA: Harvard University Press.

O'Regan, J. (2011). Why red Doesn't sound like a bell: Understanding the feel of consciousness. Cambridge: MIT Press.

O'Regan, J., \& Noë, A. (2001). A sensorimotor account of vision and visual consciousness. Behavioral and Brain Sciences, 24(5), 939-1031.

Pinto, Y., Neville, D., Otten, M., Corballis, P., Lamme, V., de Haan, E., Foschi, N., \& Fabri, M. (2017). Split brain: divided perception but undivided unconsciousness. Brain, 140(5), 1231-1237.

Schechter, E. (2014). Partial Unity of consciousness: A preliminary defense. In D. Bennett \& C. Hill (Eds.), Sensory Integration and the Unity of Consciousness (p. Ch. 15). Cambridge: MIT Press.

Schwitzgebel, E. (2015). If materialism is true, the United States is probably conscious. Philosophical Studies, 172(7), 1697-1721. 
Thompson, E. (2007). Mind in life: Biology, phenomenology, and the sciences of the mind. Cambridge: Harvard University Press.

Tovar-Moll, F., Monteiro, M., Andrade, J., Bramati, I., Vianna-Barbosa, R., Marins, T., et al. (2014). Structural and functional brain rewiring clarifies preserved interhemispheric transfer in humans born without the corpus callosum. Proceedings of the National Academy of Sciences of the United States of America, 111(21), 7843-7848.

Tye, M. (1995). Ten problems of consciousness: A representational theory of the phenomenal mind. Cambridge: MIT Press.

Tye, M. (2000). Consciousness, colour, and content. Cambridge: MIT Press.

Tye, M. (2003). Consciousness and persons. Cambridge: MIT Press.

Varela, F., Thompson, E., \& Rosch, E. (1991). The embodied mind. Cambridge: MIT Press.

Wheeler, M. (2010). In defense of extended functionalism. In: R. Menary (Ed.), The Extended Mind. Cambridge: MIT Press. 